Journal of Social Sciences 7 (3): 451-455, 2011

ISSN 1549-3652

(C) 2011 Science Publications

\title{
The Role of the Jordanian Media in Raising Awareness of the Democratic Election
}

\author{
Heba Hammad and Mustafa Ayroutt \\ Princess Alia College, Balqa Applied University, Jordan
}

\begin{abstract}
Problem statement: We ty to identify the role of Jordanian media in spreading awareness of the democratic election from the viewpoint of a sample of students in the faculties of university in Jordan. Approach: The search tool consisting of 24 paragraphs were utitlized on a sample of 100 students. Results: Results showed that differences were not statistically significant according to place of residence. The results indicated that the specialty as a function at the level of significance 0.05 for the benefit of students. Conclusion: We condcluded that the assessment of students to the role of the media was average and preferably better than that.
\end{abstract}

Key words: Jordanian media, democratic election, undergraduate college students, Special Education, search tool, electoral process, political participation, economic factors, education Laws, youth category

\section{INTRODUCTION}

Supports young people aged (18-30) on the media, including television to get information on all aspects of political, social, economic and this measured level of democratic awareness of you in the family since childhood and how women's participation in the political aspects and organic In civic associations and social organizations.

In a study of Jordanian culture of democracy, entitled "Monitoring the media coverage and civil official of the parliamentary elections in Jordan in 2007. "Where the report concluded Announcements elections harvested large areas of all media by clear and especially newspapers and that there was a low turnout on advertising through television, images and ads occupies space up in the website and recommended the allocation of special programs in all media for voter education Laws and procedures of the electoral process to support the political participation of all segments of society. (Stevens and Griego, 2009)

In a study of under the title "social constraints to the participation of Jordanian women in the political sphere", which aimed to identify the status of women and their social and political in Jordanian society and to identify the size of the political participation of Jordanian women? The study found that Jordanian women are still far from the awareness of the importance of political participation and presence is still in positions of political decision-making is not commensurate with the intensity of its presence in the areas of education. And where this study recommended paying attention to and raising women's political awareness and increasing her chances of making political decisions.

And in the study which aimed to identify the role of television in educating young people of Jordan during the parliamentary elections in 2007, which amounted to the study sample of 600 individuals of 1830 years in a region north and the center and south, which concluded that the More connectivity issues suffered by young people during the campaign in favor of rallies by $40.8 \%$ and television came ranked seventh by $21.3 \%$. The results also showed that the Jordanian TV has had a weak role in educating young people during the parliamentary elections and that the adoption of young people on TV to know the local affairs were intermediate and the percentage of those who have followed the election programs of the (home voice, voice) of the young people was 32.8 and $18.5 \%$ respectively of the total sample. This is what shows that the Jordanian TV, not a source of knowledge to the youth category of the research sample

And In a study Which aimed to find out the reasons that led to the decline of political awareness among university students and political participation also in community affairs and issues of the day and know the role of the media and especially television in political

Corresponding Author: Heba hammad, Mustafa Ayroutt, Balqa Applied University, Princess Alia College, Amman, P.O. Box: 364, Amman 11821, Jordan 


\section{J. Social Sci., 7 (3): 451-455, 2011}

awareness and stimulate political participation among the youth of the universities, legate (100) students and students from the Faculty of Social Work at the University of Cairo, the results show that (39.2\%) are keen to always watch television and (57.7\%) and sometimes they are seeing $(2.1 \%)$ they see rarely and that the programs that relate to political life has taken middleranking Of the concerns of the research sample, which indicates the low political awareness and political participation of members of the sample.

\section{MATERIALS AND METHODS}

Many of the research and studies addressed the rates of political participation of women in political parties or trade unions or the House of Representatives of Jordan to reach all of the weakness of political participation, nominations, uh, vote, although its development and improvement of the seventies and nineties, but they are still weak, according to what you wish for political leadership, notwithstanding the equality of men and Women in political rights and although the Jordanian media gives a positive image of the political participation of Jordanian women and had attributed a lot of studies of obstructions multiple to the continued lack of community acceptance of women's work in the political sphere and the lack of financial independence for women and other difficulties due to social factors and Of a culture and awareness of women to political and economic factors and information.

\section{Tries to find the answer to the following questions:}

- What is the role of the Jordanian media in spreading awareness of the democratic election from the viewpoint of a sample of undergraduate college students high depending on the place of residence

- What is the role of the Jordanian media in raising awareness of democratic elections from the perspective of a sample of undergraduate college students high depending on academic year

- What is the role of the Jordanian media in spreading awareness of the democratic election from the viewpoint of a sample of undergraduate college students high depending on the specialty

Was the formulation of 24 paragraphs and arbitration procedure And to verify the veracity of the search tool is applied to the sample of 100 students with the procedures for factor analysis orthogonal to paragraphs she stated that the results that all items had been saturated by a factor of a single interpreted (0.49) of the variance overall interpreter while interpreted the second factor (0.19) of the whole variance, which demonstrates that the Paragraphs in the most saturated the first factor, which built the search tool for.

\section{RESULTS}

According to place of residence: Analysis of variance performance of students according to place of residence shows the averages and standard deviations for the sample of placing

The previous tables show that the differences in the performance of students on Identify according to place of residence were not a function. And make averages and standard deviations of the data and comparisons to know a posteriori the average performance results were as described in the following Table 1-11.

Scheffe a posteriori comparisons depending on the accommodation.

Identification of the preceding tables that the average performance of students on the search tool in Amman was (65.44) while (67.04) and (64.80) for students who live in the provinces of Amman and villages respectively. And a posteriori comparisons show that the differences between residents of the capital Amman and villages was not statistically significant for all groups, indicating that the level of performance was close.

According to academic year: And study the differences in performance depending on the academic year the results were as follows:

- Analysis of variance depending on the performance of students for the academic year:

- The previous table shows that the differences in the performance of students on the search tool according to the academic year as the value indicative of the significance level (0.000) and study the averages and standard deviations of the data and comparisons a posteriori the knowledge for the benefit of any year were the following tables

- Averages and standard deviations of the sample for the academic year

Multiple comparisons: Comparisons a posteriori the Scheffe depending on the academic year

Seen from the preceding tables that the average performance of students was the first year (59.69) and for the second year (61.34) and (71.19) for the third year in a while for the fourth year (68.97). And study a posteriori the Scheffe comparisons showed that the differences were in favor of the third year for the first year and 


\section{J. Social Sci., 7 (3): 451-455, 2011}

second as it reached the significance level $(0.000)$ in both cases, which shows that the performance of students of the third category is the best.

According to specialty: Analysis of variance performance of students depending on the specialty Averages and standard deviations of the sample depending on the specialty.

Illustrates the preceding tables that the differences in the performance of students on the research instrument was a function at the level of significance (0.02 depending on the specialty, with an average performance of students allocated child-rearing (64.06) and (66.74) for students of English Language and (60.04) for Special Education and (67.83) to manage the business . and study a posteriori the Scheffe comparisons to know for the benefit of any discipline were the results, as illustrated by the following Table 1-11.

Comparisons a posteriori the Scheffe depending on specialty.

Table 1:

\begin{tabular}{llll}
\hline No & $\begin{array}{l}\text { Standard } \\
\text { deviation }\end{array}$ & Mean & Place \\
\hline 84 & 12.792 & 65.44 & Amman \\
67 & 11.313 & 67.04 & Governorate \\
35 & 13.843 & 64.80 & Village \\
186 & 12.453 & 65.90 & Total \\
\hline
\end{tabular}

Table 2:

\begin{tabular}{lll}
\hline & Initial eigenvalues & \\
Percentage of variance & Total & Component \\
\hline 49.226 & 11.814 & 1 \\
19.47 & 4.6730 & 2 \\
13.498 & 3.2400 & 3 \\
6.149 & 1.4760 & 4 \\
4.539 & 1.0890 & 5 \\
3.172 & 0.7610 & 6 \\
2.195 & 0.5270 & 7 \\
1.136 & 0.2730 & 8 \\
0.615 & 0.1480 & 9 \\
\hline
\end{tabular}

Table 3:

\begin{tabular}{|c|c|c|c|c|c|}
\hline $\begin{array}{l}\text { Significan } \\
\text { level }\end{array}$ & ance & $\begin{array}{l}\text { Mean of } \\
\text { squares }\end{array}$ & DF & $\begin{array}{l}\text { Sum of } \\
\text { squares }\end{array}$ & Source \\
\hline 0.623 & 0.474 & 73.946 & 2 & 147.891(a) & Corrected model \\
\hline & 4504.184 & 702533.800 & 1 & 702533.800 & Intercept \\
\hline \multirow[t]{4}{*}{0.623} & 0.474 & 73.946 & 2 & 147.891 & place \\
\hline & & 155.974 & 183 & 28543.168 & Error \\
\hline & & & 186 & 836401.000 & Total \\
\hline & & & 185 & 28691.059 & Corrected total \\
\hline
\end{tabular}

Table 4:

\begin{tabular}{|c|c|c|c|c|}
\hline $\begin{array}{l}\text { Significance } \\
\text { level }\end{array}$ & Std. Error & $\begin{array}{l}\text { Mean } \\
\text { difference }\end{array}$ & (J) place & (I)place \\
\hline 0.713 & 2.046 & -1.6 & Governorate & Amman \\
\hline 0.965 & 2.513 & 0.64 & Village & \\
\hline 0.713 & 2.046 & 1.6 & Amman & Governorate \\
\hline 0.665 & 2.605 & 2.24 & Village & \\
\hline 0.965 & 2.513 & -0.64 & Amman & Village \\
\hline 0.665 & 2.605 & -2.24 & Governorate & \\
\hline
\end{tabular}

Table 5:

\begin{tabular}{|c|c|c|c|c|c|}
\hline \multicolumn{2}{|c|}{ Significance } & $\begin{array}{l}\text { Mean } \\
\text { of squares }\end{array}$ & DF & $\begin{array}{l}\text { Sum of } \\
\text { squares }\end{array}$ & Source \\
\hline $\begin{array}{l}0.000 \\
\text { model }\end{array}$ & 11.063 & 1475.021 & 3 & $4425.062(a)$ & Corrected \\
\hline 0.000 & 5365.077 & 715323.890 & 1 & 715323.890 & Intercept \\
\hline 0.000 & 11.063 & 1475.021 & 3 & 4425.062 & academic year \\
\hline & & 133.330 & $\begin{array}{l}182 \\
186\end{array}$ & $\begin{array}{l}24265.997 \\
836401.000\end{array}$ & $\begin{array}{l}\text { Error } \\
\text { Total }\end{array}$ \\
\hline & & & 185 & 28691.059 & Corrected total \\
\hline
\end{tabular}

Table 6:

\begin{tabular}{lrrrcl}
\hline \multicolumn{2}{l}{$\begin{array}{l}\text { Significance } \\
\text { level }\end{array}$} & \multicolumn{1}{c}{ F } & $\begin{array}{c}\text { Mean of } \\
\text { squares }\end{array}$ & DF & \multicolumn{1}{c}{$\begin{array}{l}\text { Sum of } \\
\text { squares }\end{array}$} \\
\hline 0.026 & 3.158 & 473.203 & 3 & $1419.610(\mathrm{a})$ & Corrected model \\
0.000 & 3477.545 & 521086.100 & 1 & 521086.100 & Intercept \\
0.026 & 3.158 & 473.203 & 3 & 1419.610 & specialty \\
& & 149.843 & 182 & 27271.450 & Error \\
& & & 186 & 836401.000 & Total \\
& & & 185 & 28691.060 & Corrected total \\
\hline
\end{tabular}

Table 7:

\begin{tabular}{|c|c|c|c|c|}
\hline No & Standard deviation & \multirow{2}{*}{$\begin{array}{l}\text { Nivean } \\
59.69\end{array}$} & \multicolumn{2}{|c|}{ Academic year } \\
\hline 29 & 7.996 & & 1 & \\
\hline 58 & 13.011 & 61.34 & 2 & \\
\hline 63 & 11.93 & 71.19 & 3 & \\
\hline 36 & 10.694 & 68.97 & 4 & \\
\hline 186 & 12.453 & 65.9 & \multicolumn{2}{|c|}{ Total } \\
\hline \multicolumn{5}{|l|}{ Table 8: } \\
\hline $\begin{array}{l}\text { Significance } \\
\text { level }\end{array}$ & Std. error & $\begin{array}{l}\text { Mean } \\
\text { difference }\end{array}$ & (J) year & (I) year \\
\hline 0.922 & 2.626 & -1.66 & 2 & 1 \\
\hline 0.000 & 2.591 & $-11.50(*)$ & 3 & \\
\hline 0.008 & 2.881 & $-9.28(*)$ & 4 & \\
\hline 0.922 & 2.626 & 1.66 & 1 & 2 \\
\hline 0.000 & 2.101 & $-9.85(*)$ & 3 & \\
\hline 0.011 & 2.450 & $-7.63(*)$ & 4 & \\
\hline 0.000 & 2.591 & $11.50(*)$ & 1 & 3 \\
\hline 0.000 & 2.101 & $9.85(*)$ & 2 & \\
\hline 0.794 & 2.412 & 2.22 & 4 & \\
\hline 0.002 & 2.881 & $9.283(*)$ & 1 & 4 \\
\hline 0.002 & 2.450 & 7.627(*) & 2 & \\
\hline 0.359 & 2.412 & -2.218 & 3 & \\
\hline
\end{tabular}

Table 9:

\begin{tabular}{llll}
\hline No & Standard deviation & mean & specialty \\
\hline 36 & 16.276 & 64.06 & child-rearing \\
19 & 10.744 & 66.74 & English language \\
26 & 8.219 & 60.04 & Special education \\
105 & 11.699 & 67.83 & Business administration \\
186 & 12.453 & 65.90 & Total \\
\hline
\end{tabular}

Table 10:

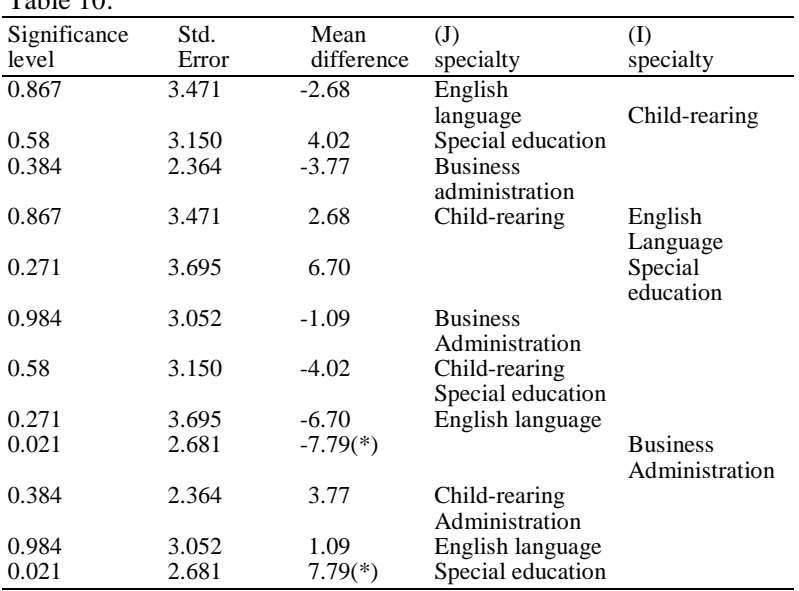




\section{J. Social Sci., 7 (3): 451-455, 2011}

Table 11:

\begin{tabular}{|c|c|c|c|}
\hline $\begin{array}{l}\text { N of Items } \\
24\end{array}$ & & & $\begin{array}{l}\text { Cronbach's Alpha } \\
0.819\end{array}$ \\
\hline \multicolumn{4}{|l|}{ Table 12: } \\
\hline $\begin{array}{l}97-120 \\
\text { excellent }\end{array}$ & $\begin{array}{l}73-96 \\
\text { good }\end{array}$ & $\begin{array}{c}49-72 \text { medium } \\
\text { ******* }\end{array}$ & $\begin{array}{l}24-48 \\
\text { week }\end{array}$ \\
\hline
\end{tabular}

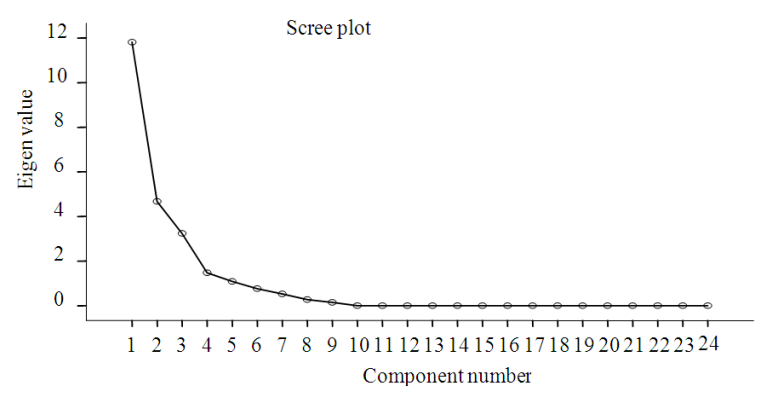

Fig. 1:

The previous table shows the degree of persistence in accordance with Cronbach alpha and It is clear from the above table that the differences between a specialized business management and special education was indicative of when the level of significance (0.02) for the benefit of students of Business Administration with an average performance of special education students (60.04) while (67.83) to business.

The value of reliability coefficient Cronbach alpha according to the research sample value $(0.819)$ and is good value for research purposes as shown in the following table. The stability of the value of Cronbach alpha.

This Fig. 1 Shows the Line shows how saturated paragraphs 24 factors measured by the tool, urged shows that the factors saturated by a factor of one clear (high saturation) confirm the tool in the measurement of one attribute and that is between them without the intervention of other factors saturation high impact on the sincerity of the tool as a result of the factor analysis

\section{DISCUSSION}

An analysis of variance for the performance of students on the search tool according to place of residence she stated that the results show that these differences were not statistically significant, with an average performance of students on the search tool in Oman (65.44) while (67.04) to the provinces and (64.80) for the villages. Which proves that these small differences statistically significant to prove nonconvergence of performance levels depending on the accommodation and the fact that the media these days for all groups up to provide technology and electronic media and DVB and other satellite channels. While the differences in performance on the search tool according to the academic year indicative as the value the significance level (0.000) for the benefit of students of the third year the students the first year and the second with an average performance of students the first year was (59.69) and for the second year (61.34) and (71.19) for the third year in a while for the fourth year (68.97), which shows that the increase of years of academic contribute to the exposure to the various media that feeling more and more turn. Most of the fourth year students are married, which led to a decrease their performance on the third year students and better than the first and two female students.

And study the differences in performance on the search tool depending on the specialty results indicated that they function at the level of significance $(0.02)$ as the average performance of students allocated childrearing (64.06) and (66.74) for students of English Language and (60.04) for Special Education and (67.83) to manage the business For the benefit of students of Business Administration students to special education to play a role in the specialization of students and always attention of the media.

\section{CONCLUSION}

Were compared with the average performance of students according to the factors on a scale of 4 categories depending on the total points on the search tool after the patch, So it is clear they are all medium to all the factors Reached between all medium (49-72).

Answers to the most low, respectively, where the rates exceeded $80 \%$ of students who answered them not to and I do not know and a little bit. Where she spoke paragraph 5, to connect the student with the Ministry of Political Development for any queries and talked paragraph 4, the number of seats for women's quota and talked paragraph 12 about the availability of films and documentaries about the role of elections in the decision-making and talked paragraph 18 on the availability of an animated children's sense of election. Spoke paragraph 16 about the availability of education programs of democracy in the Jordanian media throughout the year and talked, paragraph 7, the feeling of students that all things are clear media, which demonstrates the weakness of the media in electoral education necessary for women of Jordan and Jordanian women as a basis for awareness of democracy necessary bring in the Jordanian society forthcoming. 


\section{REFERENCES}

Drew, D. and D. Weaver, 2004. Voter learning in the 2004 presidential election: did the media matter. J Mass Commun. Q., .83: 25-42. http://direct.bl.uk/bld/PlaceOrder.do?UIN=188945 $969 \& \mathrm{ETOC}=\mathrm{RN} \&$ from $=$ searchengine
Kaid, L.L., 2004. Handbook of Political Communication Research. 1st Edn., Routledge, London, ISBNL: 0805837744, pp: 541.

Stevens, R.H. and O. Griego, 2009. Evaluating experiential learning in organizational behavior: taking measure of student perception regarding group experience. Am. J. Econ. Bus. Admin., 1: 138-140. DOI: 10.3844/ajebasp.2009.138.140 